\title{
Antitumor effects of ribavirin in combination with TMZ and IFN- $\beta$ in malignant glioma cells
}

\author{
YUSHI OCHIAI $^{1 *}$, KOICHIRO SUMI $^{1 *}$, EMIKO SANO $^{2}$, SODAI YOSHIMURA $^{1}$, SHUN YAMAMURO $^{1}$, \\ AKIYOSHI OGINO ${ }^{1}$, TAKUYA UEDA ${ }^{2}$, YUTAKA SUZUKI ${ }^{2}$, TOMOHIRO NAKAYAMA ${ }^{3}$, \\ HIROYUKI HARA $^{4}$, YOICHI KATAYAMA ${ }^{1,5}$ and ATSUO YOSHINO ${ }^{1}$ \\ ${ }^{1}$ Department of Neurological Surgery, Nihon University School of Medicine, Tokyo 173-8610; \\ ${ }^{2}$ Department of Computational Biology and Medical Science, Graduate School of Frontier Sciences, \\ The University of Tokyo, Chiba 277-8562; ${ }^{3}$ Division of Companion Diagnostics, Department of Pathology and Microbiology; \\ ${ }^{4}$ Division of Functional Morphology, Department of Functional Morphology, Nihon University School of Medicine, \\ Tokyo 173-8610; ${ }^{5}$ Center for Brain and Health Sciences, Aomori University, Aomori 038-0003, Japan
}

Received April 2, 2020; Accepted July 14, 2020

DOI: $10.3892 / \mathrm{ol} .2020 .12039$

\begin{abstract}
The prognosis of gioblastoma, the standard chemotherapy agent for which is temozolomide (TMZ), remains poor despite recent advances in multimodal treatments. Therefore, it is necessary to identify and develop novel therapeutics for this malignant disease. Ribavirin, an anti-viral agent which is one of the standard agents for treatment of chronic hepatitis $\mathrm{C}$ in combination with interferon (IFN), was recently revealed to have an antitumor potential towards various tumor cells, including malignant glioma cells. The aim of the present study was to examine the antitumor effect of ribavirin in combination with TMZ and IFN- $\beta$ on glioma cells and to evaluate the possibility that such combinations might represent a novel candidate for glioblastoma therapy. The combination of ribavirin with TMZ and IFN- $\beta$ displayed a significant cell growth inhibitory effect with a ribavirin dose-dependency, including a relatively low concentration of ribavirin, on not only TMZ-sensitive but also TMZ-resistant malignant glioma cells. The antitumor efficacy of such a combination further indicated a synergistic interaction when assessed by the Chou-Talalay method. Furthermore, flow cytometry analysis suggested that apoptosis induction was one of the possible biological processes underlying the synergistic antitumor effect of these triple combination treatments. Therefore, such combinations may be potentially important in the clinical
\end{abstract}

Correspondence to: Dr Atsuo Yoshino, Department of Neurological Surgery, Nihon University School of Medicine, 30-1 Oyaguchi-Kamimachi, Itabashi-ku, Tokyo 173-8610, Japan

E-mail: yoshino.atsuo@nihon-u.ac.jp

*Contributed equally

Key words: glioblastoma, ribavirin, temozolomide, interferon, apoptosis setting for glioblastoma treatment, although further detailed studies, e.g. on the adverse effects, are required.

\section{Introduction}

Although advances in multimodal therapies including surgery, radiotherapy, and chemotherapy are being made, the prognosis for glioblastomas, the most common primary brain tumor in adults and classified as having WHO grade IV malignancy, has not improved adequately for more than 30 years. In 2009, the EORTC/NCIC reported final results indicating the benefits of concomitant and adjuvant temozolomide (TMZ: a relatively new alkylating agent) in addition to standard postoperative radiotherapy for glioblastomas (1). Subsequently, concomitant radiotherapy with $\mathrm{TMZ}$ followed by adjuvant $\mathrm{TMZ}$ chemotherapy has become the current and global standard treatment for malignant gliomas, especially glioblastomas. Even though such treatments show a survival benefit in glioblastoma patients, the prognosis deriving from these therapies remains unsatisfactory.

Ribavirin, first reported in 1972 by Sidwell et al (2) as an anti-viral agent, is a nucleic acid analog. To date, ribavirin has served as a therapeutic agent widely used against RNA and DNA viruses, and is in particular one of the standard agents for chronic hepatitis $\mathrm{C}$ combined with interferon (3). On the other hand, we and others have recently observed an anti-tumor effect of ribavirin on various tumor cells, including breast cancer, acute myeloid leukemia, and atypical teratoid/rhabdoid tumors, which is thought to be mediated via inosine-5'-monophosphate dehydrogenase (IMPDH), eukaryotic translation initiation factor $4 \mathrm{E}$ (eIF4E), histone methyltransferase enhancer of zeste homolog 2 (EZH2), extracellular regulated protein kinases (ERK), and/or mitogen-activated protein kinase interacting protein kinase 1 (MNK1) (3-11). To date, there have been only a few studies on the anti-tumor effect of ribavirin against glioma cells. Volpin et al (9) reported an anti-tumor effect of ribavirin including in combination with TMZ and irradiation on glioma cells and glioma stem-like cells in vivo 
and in vitro. More recently, we demonstrated an effect of ribavirin on apoptosis induction, cell cycle arrest, p53 pathway activation, and DNA damage (double-strand breaks: DSBs) in malignant glioma cell lines (10).

In the present study, we obtained further data by examining the effect of ribavirin in combination with TMZ and interferon-beta (IFN- $\beta$ ) on malignant glioma cells. The reasons for using TMZ and IFN- $\beta$ in combination with ribavirin were that TMZ is a standard chemotherapeutic agent for glioblastomas as mentioned above, and IFN- $\beta$ exhibits pleiotrophic biological activities against neoplasias (12-15) and acts as a drug sensitizer enhancing the anti-tumor effect when administered in combination with nitrosoureas (alkylating agents) against malignant gliomas (16). Furthermore, a synergistic anti-tumor effect between TMZ and IFN- $\beta$ has been demonstrated in malignant glioma cells (17-19), and a significant anti-tumor effect of ribavirin in combination with IFN- $\alpha$ (grouped to type I IFNs, the same as IFN- $\beta$ ) has been observed in hepatoma cells and renal carcinoma cells $(20,21)$. Based on the findings of the present study, the combination of these three agents could exert a synergistic anti-tumor effect in malignant glioma cells and provide an experimental basis for rational clinical treatments in glioblastoma patients.

\section{Materials and methods}

Cell lines and cell culture. Human malignant glioma cells of the A-172 (cell no. JCRB0228, lot no. 021999), AM-38 (cell no. IFO50492, lot no. 12082003), T98G (cell no. IFO50303, lot no. 1007), U-251MG (cell no. IFO50288, lot no. 12132002), and YH-13 (cell no. IFO50493, lot no. 1164) cell lines were obtained from Health Science Research Resources Bank (Osaka, Japan), and U-87MG (glioblastoma of unknown origin; catalog no.: HTB-14, lot no. 2497162) and U-138MG (catalog no. HTB-16, lot no. 1104428) were procured from the American Type Culture Collection. It has been confirmed by us that $O^{6}$-methylguanine-DNA methyltransferase (MGMT: a key factor of alkylating agents) is expressed in T98G, U-138MG and YH-13 by RT-PCR and western blot analysis in a previous study (22). Consistent with an earlier report (23), it was also confirmed that T98G (237 Met $\rightarrow$ Ile) and U-251MG (273 $\mathrm{Arg} \rightarrow \mathrm{His})$ have a point mutation of the $p 53$ gene. These cell lines were cultured in Dulbecco's modified Eagle's medium (Nissui Pharmaceutical) containing 10\% fetal calf serum (Life Technologies) using plastic culture flasks (Corning ${ }^{\circledR}$ ) in a standard humidified incubator at $37^{\circ} \mathrm{C}$ under a $5 \% \mathrm{CO}_{2}, 95 \%$ air atmosphere.

Cell culture growth studies. Malignant glioma cell proliferation was evaluated using a Coulter Counter (Beckman Coulter) to determine the cell numbers in 24-well plates (Iwaki). Each well was seeded with $1 \times 10^{4}$ cells and cultured for $24 \mathrm{~h}$ prior to treatment to allow adherence of the cells to the plate. The culture medium was replenished with fresh medium containing ribavirin (0.1-100 $\mu \mathrm{M}$; Sigma) alone, or in combination with TMZ (10 $\mu \mathrm{M}$; LKT Laboratories) and IFN- $\beta(10 \mathrm{IU} / \mathrm{ml}$; Toray), and the cells were cultured for $72 \mathrm{~h}$. We selected the incubation conditions as $10 \mu \mathrm{M} \mathrm{TMZ}$ and/or $10 \mathrm{IU} / \mathrm{ml} \mathrm{IFN}-\beta$, because these values represent clinically achievable concentrations of TMZ and IFN- $\beta(19,24)$. Furthermore, in order to assess whether the effect of the combination of these agents, TMZ, IFN- $\beta$, and/or ribavirin, was synergistic, the ribavirin was set at a clinically relevant concentration of $10 \mu \mathrm{M}$ (25). The proliferated cells were harvested with trypsin-EDTA solution (Invitrogen; Thermo Fisher Scientific, Inc.) and the numbers counted. The cell culture growth experiments were repeated a minimum of four times each.

Synergism of drug combination treatment. Moreover, to confirm whether the anti-tumor effect of the combination with TMZ, IFN- $\beta$, and ribavirin was synergistic, a combination index (CI) was also calculated using the Chou-Talalay method (26). In the present study, we decided to calculate the $\mathrm{CI}$ at $50 \%$ inhibition of cell proliferation $\left(\mathrm{IC}_{50}\right)$. Two malignant glioma cell lines, A-172 and U-251MG, were therefore employed to calculate the $\mathrm{CI}$, because their $\mathrm{IC}_{50}$ values had been obtained on the basis of dose response curves. The $\mathrm{IC}_{50}$ of TMZ, IFN- $\beta$, and ribavirin for A-172 was $52.4 \mu \mathrm{M}$, $57.5 \mathrm{IU} / \mathrm{ml}$, and $53.6 \mu \mathrm{M}$, and for $\mathrm{U}-251$ was $22.5 \mu \mathrm{M}$, $26.4 \mathrm{IU} / \mathrm{ml}$, and $257.7 \mu \mathrm{M}$, respectively $(7,15,22)$. Based on the Chou-Talalay method, CI values of less than 1 are indicative of synergism (the smaller the value, the greater the degree of synergy), those equal to 1 indicate additivity, and those of more than 1 are interpreted as antagonism. Values of $\mathrm{CI}<0.4$, between 0.4 and 0.8 , and $>0.8$ indicate strong, medium and slight synergism, respectively $(26,27)$. An additive effect is defined as a situation in which the final effect is equal to the sum of the effects of the drugs. Drug interactions are interpreted as antagonistic if they lead to a decrease in the effects of one or both drugs $(26,27)$.

Assessment of apoptosis. From the results for the growth inhibitory effect and CI, U-251MG cells were subjected to further experiments. Apoptosis was analyzed by flow cytometry, using dual staining with an Annexin V-FITC/PI Apoptosis Detection Kit (BD Biosciences). Cells were seeded in 6-well plates (Iwaki) at $1 \times 10^{6}$ cells and incubated for $24 \mathrm{~h}$ to adhere. The culture medium was then replenished with fresh medium containing ribavirin, TMZ, IFN- $\beta$, TMZ and IFN- $\beta$, or TMZ, IFN- $\beta$ and ribavirin for $72 \mathrm{~h}$ (ribavirin, $10 \mu \mathrm{M}$; TMZ, $10 \mu \mathrm{M}$; IFN- $\beta, 10 \mathrm{IU} / \mathrm{ml})$. The cells were next washed in PBS and harvested using trypsin-EDTA solution. Following centrifugation and washing in PBS, the solution was agitated with $100 \mathrm{ml}$ of binding buffer (Wako Pure Chemical Industries, Ltd.), into which $5 \mu \mathrm{l}$ of Annexin V Alexa Fluor 488 conjugate (Life Technologies; Thermo Fisher Scientific, Inc.) and $10 \mu \mathrm{l}$ of PI (Miltenyi Biotech) were added, and incubated at room temperature for $10 \mathrm{~min}$. An additional $400 \mu \mathrm{l}$ of binding buffer was added to give a total sample volume of $500 \mu \mathrm{l}$. The fluorescence was measured with an FACSCalibur flow cytometer (Becton-Dickinson). The apoptotic cells were analyzed using Flowjo software (BioLegend). The experiments were repeated three times to confirm reproducibility.

Statistical analysis. Appropriate comparisons were made employing one-way analysis of variance followed by the Tukey-Kramer method among multiple comparisons using the software Stat View (Ver. 5.0; SAS Institute Inc.). Data were expressed as the means \pm standard error and were considered significant at $\mathrm{P}<0.05$. 


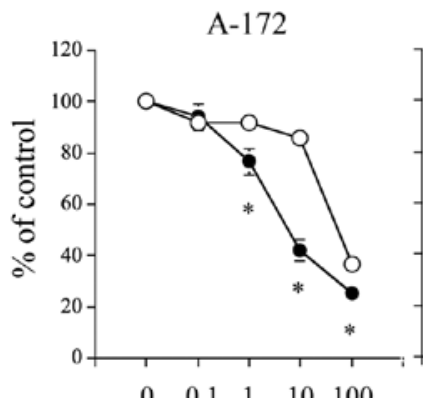

$\begin{array}{llllllll}0 & 0.1 & 1 & 10 & 100\end{array}$

Conc. of ribavirin $(\mu \mathrm{M})$
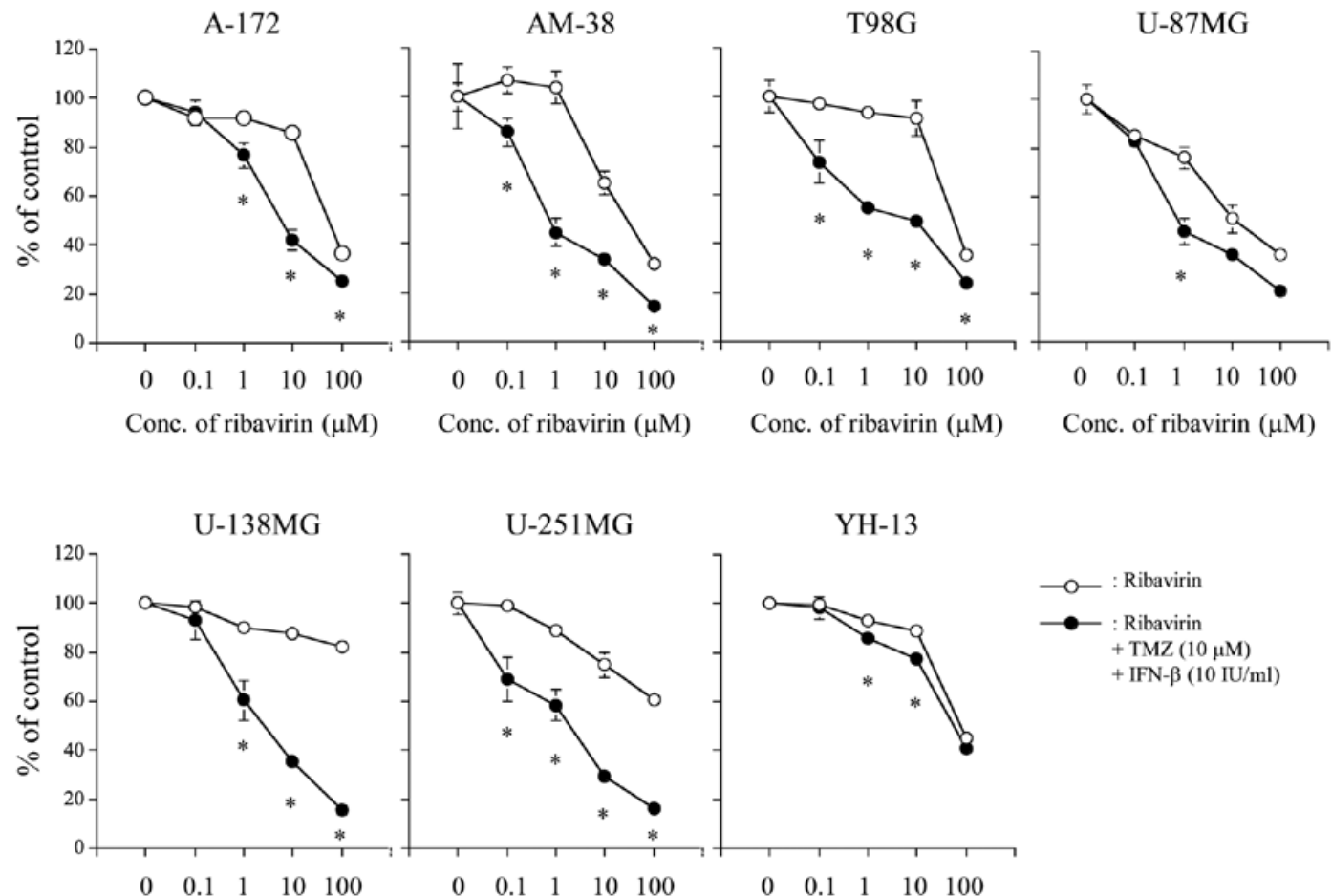

Conc. of ribavirin $(\mu \mathrm{M})$
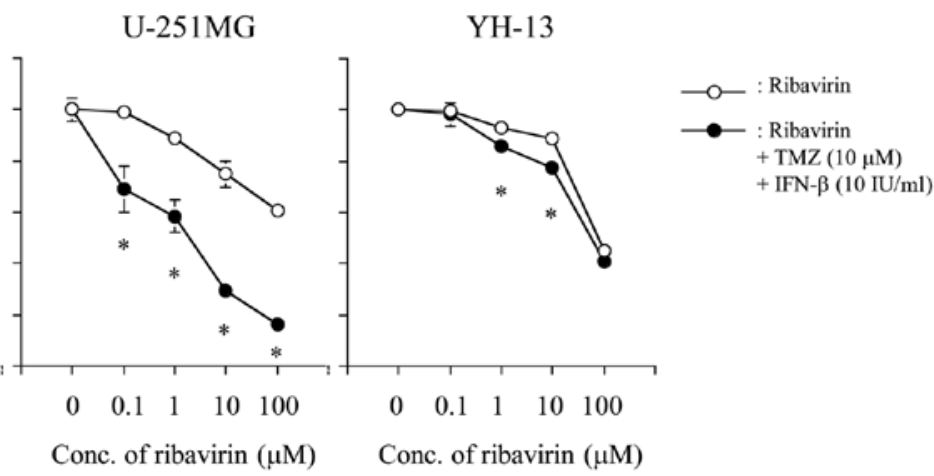

Figure 1. Cell growth inhibitory effect of a combination of ribavirin with or without TMZ and IFN- $\beta$ in seven malignant glioma derived cell lines. Malignant glioma cells were exposed to medium containing various concentrations of ribavirin without IFN- $\beta$ and TMZ (white circles) or with 10 IU/ml IFN- $\beta$ and $10 \mu \mathrm{M}$ TMZ (black circle) for $72 \mathrm{~h}$. The combination of ribavirin with TMZ and IFN- $\beta$ exerted a more profound cell growth inhibitory effect compared with ribavirin alone, with a ribavirin dose-dependency in all malignant glioma cell lines. Data are presented as the mean \pm standard error. Significant differences between ribavirin alone and the triple combination were observed at each ribavirin concentration. ${ }^{*} \mathrm{P}<0.05$. IFN- $\beta$, interferon- $\beta$; TMZ, temozolomide.

\section{Results}

Anti-tumor effects of a combination of ribavirin with TMZ and IFN- $\beta$. We have previously demonstrated an anti-tumor effect of ribavirin on malignant glioma cell lines (7). In that study, seven malignant glioma cell lines were exposed to 0.1-1,000 $\mu \mathrm{M}$ of ribavirin and treated for $72 \mathrm{~h}$, and it was found that ribavirin inhibited the growth of all seven cell lines in a dose-dependent manner (7).

To assess whether or not a combination of ribavirin with TMZ and IFN- $\beta$ could produce a more profound anti-tumor effect as compared to ribavirin alone in malignant glioma cell lines, cells were incubated in culture medium containing various concentrations $(0-100 \mathrm{IU} / \mathrm{ml})$ of ribavirin alone or ribavirin with TMZ $(10 \mu \mathrm{M})$ and IFN- $\beta$ (10 IU/ml) for $72 \mathrm{~h}$. As shown in Fig. 1, the combination of ribavirin with $\mathrm{TMZ}(10 \mu \mathrm{M})$ and IFN- $\beta(10 \mathrm{IU} / \mathrm{ml})$ revealed a significant cell growth inhibitory effect with a ribavirin dose-dependency in all seven malignant glioma cell lines. Such a cell growth inhibitory effect was also observed at a relative low concentration of ribavirin, 0.1 and $1 \mu \mathrm{M}$. Furthermore, it was evident at $0.1 \mu \mathrm{M}$ of ribavirin in AM-38, T98G, U-87MG, and U-251MG cells.

In addition, we examined whether the combination of TMZ, IFN- $\beta$, and ribavirin displayed an enhanced cell growth inhibitory effect as compared to the control, TMZ alone, or TMZ and IFN- $\beta$. As demonstrated in Fig. 2 , the cell growth inhibitory effect at $72 \mathrm{~h}$ was significantly higher in the group treated with TMZ $(10 \mu \mathrm{M})$, IFN- $\beta(10 \mathrm{IU} / \mathrm{ml})$, and ribavirin $(10 \mu \mathrm{M})$ as compared to the group treated with TMZ alone in all seven malignant glioma cell lines. Furthermore, the combination of TMZ, IFN- $\beta$ and ribavirin exerted a significantly enhanced growth inhibitory effect as compared to TMZ and IFN- $\beta$ in the AM-38, U-87MG, U-138MG, and YH-13 cells.

Drug synergy analysis of a combination of ribavirin with $T M Z$ and IFN- $\beta$. Our results indicated that the combination of TMZ, IFN- $\beta$ and ribavirin displayed significant growth inhibition in malignant glioma cells. When TMZ, IFN- $\beta$, and ribavirin were applied in combination, a synergistic effect was detected as analyzed by the Chou-Talalay method in malignant glioma cells. The CI value was 0.68 (medium synergism) in A-172 and 0.98 (slight synergism) in U-251MG at the $\mathrm{IC}_{50}$ level, respectively.

Apoptosis induced by a combination of TMZ, IFN- $\beta$, and ribavirin in $U-251 M G$ cells. The induction of apoptosis by TMZ, IFN- $\beta$, ribavirin, TMZ and IFN- $\beta$, or TMZ, IFN- $\beta$ and ribavirin in U-251MG cells was examined by Annexin V/PI double staining and evaluated using flow cytometry. The distribution of apoptotic cells (Annexin V-positive, early-stage apoptosis; Annexin V/PI-positive, late-stage apoptosis) after $72 \mathrm{~h}$ treatment is illustrated in Fig. 3. In particular, the proportion of Annexin V/PI positive cells (late-stage apoptosis) following treatment with three agents (TMZ, IFN- $\beta$ and ribavirin; mean $=10.56 \%$ ) was higher than that for each single agent (means: TMZ, 5.57\%; IFN- $\beta, 5.74 \%$; and ribavirin, $5.57 \%$, respectively). The results indicated that the apoptotic cells after treatment with three agents tend to be increased, showing 

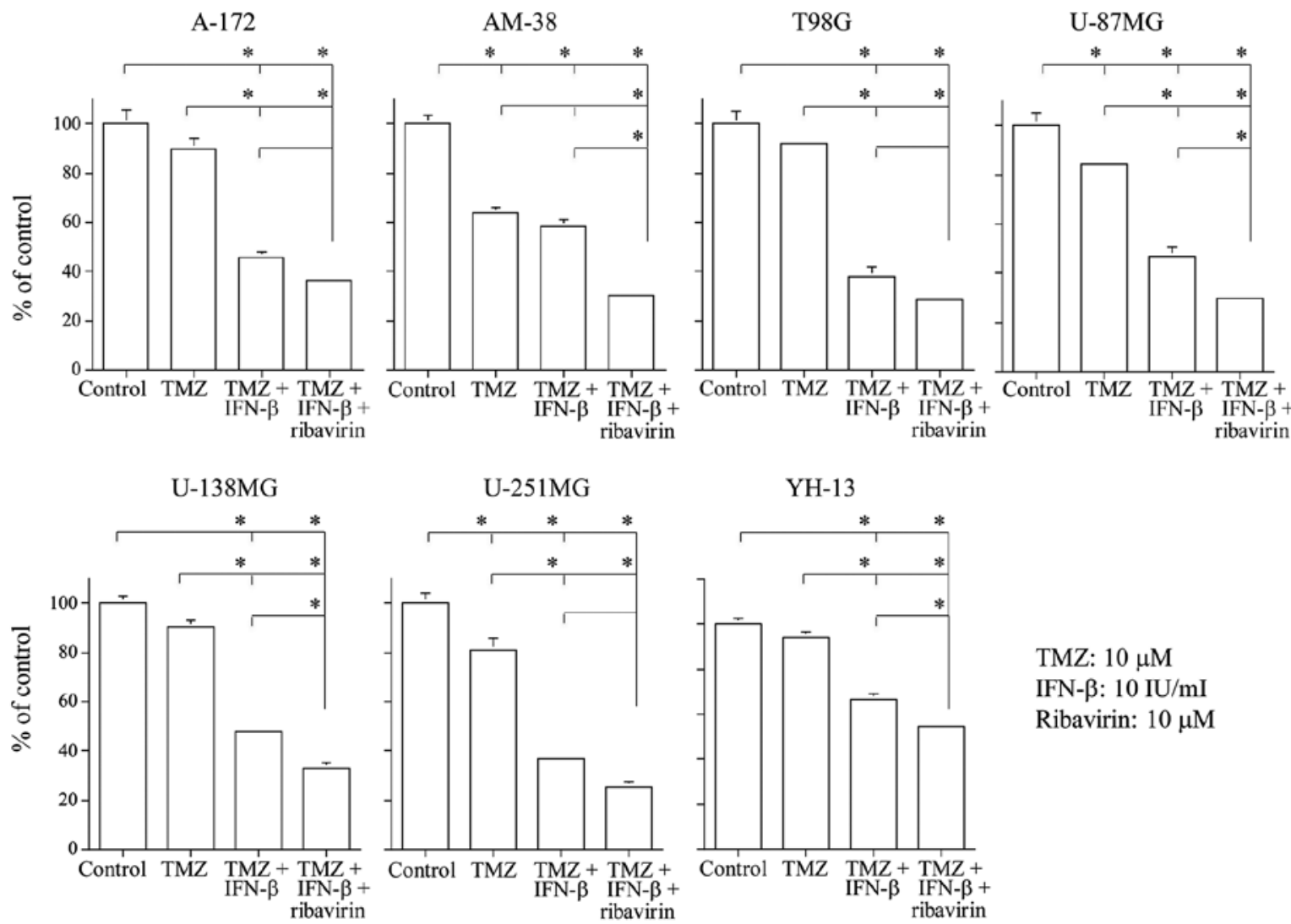

TMZ: $10 \mu \mathrm{M}$

IFN- $\beta$ : $10 \mathrm{IU} / \mathrm{mI}$

Ribavirin: $10 \mu \mathrm{M}$

Figure 2. Cell growth inhibitory effect of a combination of TMZ alone, TMZ and IFN- $\beta$, or TMZ, IFN- $\beta$ and ribavirin in seven malignant glioma cell lines. A significant synergistic cell growth inhibitory effect was observed with the combination of TMZ, IFN- $\beta$ and ribavirin in all seven glioblastoma cell lines. The results are presented as the mean \pm SE. The Tukey-Kramer test was employed to identify which group differences accounted for the significant P-values ${ }^{*} \mathrm{P}<0.05$. IFN- $\beta$, interferon- $\beta$; TMZ, temozolomide.

an elevation of more than $2 \%$ between each treatment, in U-251MG cells. However, the fact that statistically significant differences were not found among the treatments might reflect the small numbers in each group.

\section{Discussion}

TMZ has become the current first-line chemotherapeutic agent, but it does not provide satisfactory benefits for glioblastoma patients. Further studies are needed to improve the clinical therapeutic efficacy and to establish a therapeutic strategy for glioblastomas. On the other hand, we demonstrated a dose-dependent anti-tumor efficacy of ribavirin for malignant glioma cell lines (7). Recently, Volpin et al (9) showed that ribavirin $(30 \mu \mathrm{M})$ inhibited cell proliferation and migration, and increased cell arrest and cell death in glioma cells, potentially through modulation of the elF4E, EZH2, and ERK pathways. Furthermore, they indicated that ribavirin combined with TMZ $(100 \mu \mathrm{M})$ and irradiation (5 Gy) could potentially enhance the anti-tumor response in glioma cells and glioma stem-like cells, and that animals treated with a combination of ribavirin, irradiation, and TMZ had a significantly increased survival time (9). More recently, we found that ribavirin $(10 \mu \mathrm{M})$ exerts an anti-tumor effect on malignant glioma cells via the biological processes of induction of DSBs, cell cycle arrest in $\mathrm{G}_{0} / \mathrm{G}_{1}$, and both exogenous and endogenous apoptosis (10). Moreover, such effects might not be dependent on MGMT expression, which is closely correlated with resistance to TMZ treatment (10).
In the present study, the combination of ribavirin with TMZ and IFN- $\beta$ (clinically achievable concentrations) revealed a more profound cell growth inhibitory effect as compared to ribavirin alone with a ribavirin dose-dependency, which was observed from a relatively low concentration of ribavirin, in all seven malignant glioma cell lines (Fig. 1), suggesting that ribavirin has some anti-tumor effect as a medical drug. Although TMZ $(10 \mu \mathrm{M})$ did not show a cell growth inhibitory effect in A-172, T98G, U-138MG, and YH-13, the combination of ribavirin with TMZ and IFN- $\beta$ did exhibit a significant cell growth inhibitory effect in these cell lines. Out of the four cells, U-138MG and YH-13 displayed a significant cell growth inhibitory effect when treated with ribavirin, TMZ, and IFN- $\beta$ as compared to the effect without ribavirin (Fig. 2). These findings suggested that the combination of ribavirin with TMZ and IFN- $\beta$ revealed a more significant cell growth inhibitory effect in not only TMZ sensitive cells but also in TMZ resistant cells. Furthermore, in this study, the anti-tumor efficacy of a combination of these three agents on A-172 and U-251MG cells indicated a synergistic interaction when assessed by the Chou-Talalay method [A-172 and U-251MG were used in the analysis because the $\mathrm{IC}_{50}$ for each drug had been obtained $(7,22)$ ]. Such a combination of ribavirin with TMZ and IFN- $\beta$ might therefore be considered as an effective treatment in certain glioblastoma cells, although, to the best of our knowledge, no report has yet described the detailed effect of such a combination on glioma cell lines and other cell lines. 

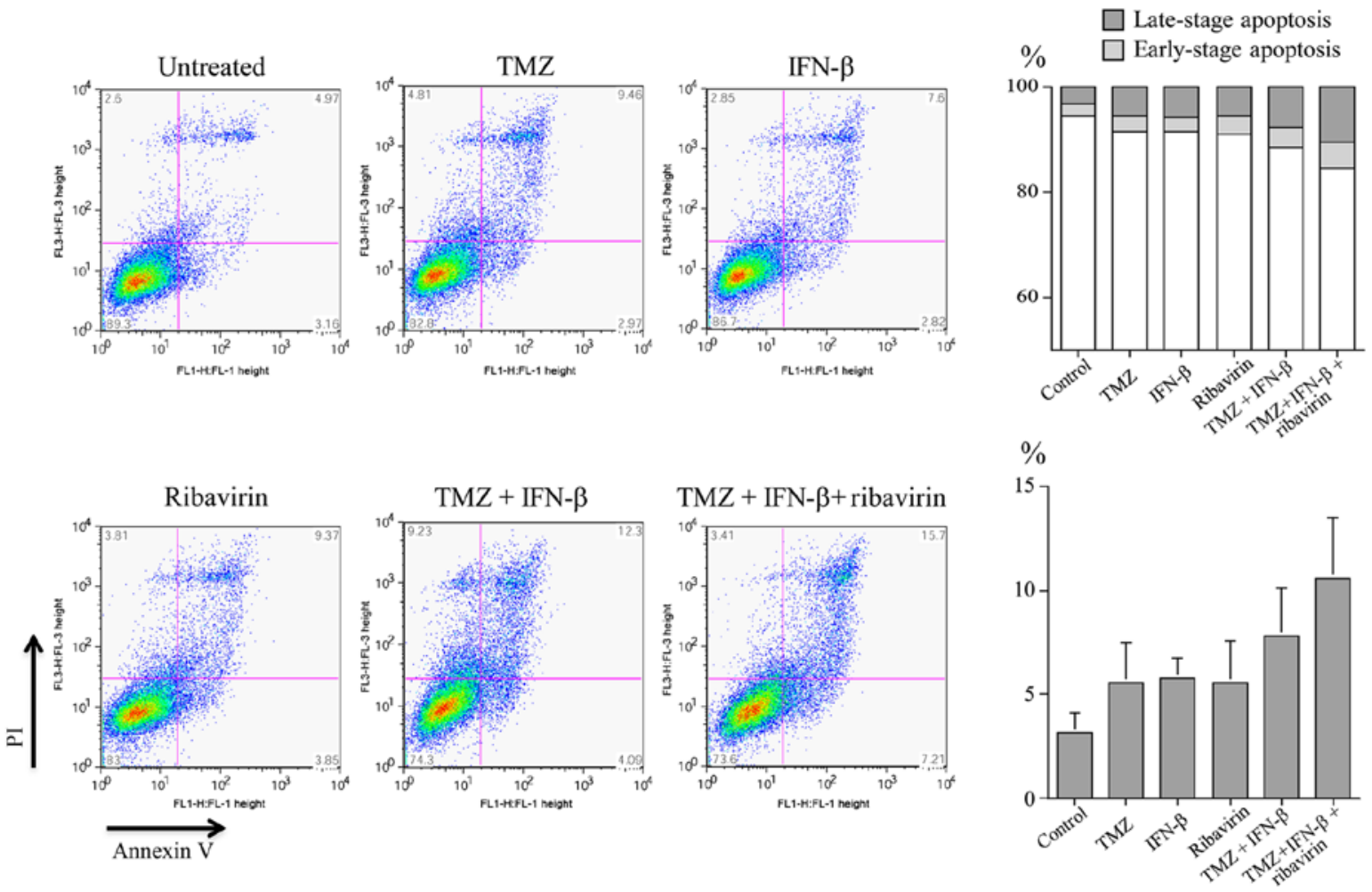

Figure 3. Induction of apoptosis by TMZ, IFN- $\beta$, ribavirin, TMZ and IFN- $\beta$, or TMZ, IFN- $\beta$ and ribavirin in U251MG cells. The ratio of detection of Annexin V-positive and Annexin V/PI-positive cells, indicating early-stage apoptosis, and late-phase apoptosis or necrosis, respectively, was measured by fluorescence-activated cell sorting after $72 \mathrm{~h}$ of treatment. The percentage of Annexin V-positive cells and the percentage of Annexin V/PI-positive cells was increased as shown at the bottom right and top right, respectively. The mean distributions of apoptotic cells with each drug and the combination are illustrated on the right. IFN- $\beta$, interferon- $\beta$; TMZ, temozolomide.

Although the mechanism underlying the anti-viral and anti-tumor effects of ribavirin has not yet been fully elucidated, several participating/possible processes have been mentioned above. Kast et al (28) pointed out the following major mechanisms of action, particularly related to the anti-viral action: i) actual intermingling within the viral RNA; ribavirin enters the cell via a nucleoside transport mechanism, subsequently inhibiting/altering viral RNA synthesis, ii) structural analogy to GTP; incorporation into the cell passively, then binding/inhibiting RNA polymerase/RNA synthesis, iii) immune clearance; immune-stimulation by up-regulation of cytokines to shift the Th1/2 cell balance to Th1 dominance, iv) inhibition of eIF4E; thereby inhibiting mRNA capping and translation initiation, v) modulation of IFN-related gene expression, vi) inhibition of IMPDH; with consequent depletion of intracellular GTP, and vii) RNA mutagen; following triphosphorylation, ribavirin triphosphate is incorporated into replicating RNA viral RNA polymerases with consequent induction of viral mutagenesis. These processes are attractive as factors in the repurposing of the anti-viral ribavirin as an anti-tumor agent, and also in the mechanism underlying the synergistic effect of ribavirin in combination with other agents. In particular, the modulation of IFN-related gene expression is thought to be a potential factor in the synergistic effect of ribavirin with $\operatorname{IFN}(13,19)$, since IFN exerts a priming effect on the ribavirin-induced IFN-related gene (29). Further studies investigating the molecular mechanisms are clearly needed to reaffirm the efficacy of these combinations.
In the present study, the flow cytometry analysis might indicate that apoptosis induction represented one possible biological process associated with the synergistic anti-tumor effect of triple combination treatment, because the apoptotic cells after such triple treatment tended to be increased in U-251MG, although no statistically significant differences were observed. Schlosser et al (20) demonstrated that ribavirin and IFN enhanced apoptosis and caspase activation in hepatoma cells. Further, Teng et al (21) showed that ribavirin in combination with IFN could significantly inhibit the cell proliferation and migration, induce apoptosis, arrest the cell cycle, and decrease IL-10 production in renal carcinoma cells. On the basis of these findings, we propose that ribavirin in combination with TMZ and IFN- $\beta$ could increase apoptosis in glioblastoma cells.

Finally, and very importantly, we need briefly to mention other effects of the drug combination used in this study. Chemotherapy-induced toxicity is a major problem in anti-tumor therapy. A cell growth inhibitory effect was also observed at a relatively low concentration of ribavirin $(0.1$ and $1 \mu \mathrm{M})$ in some glioma cell lines, AM-38, T98G, U-87MG, $\mathrm{U}-138 \mathrm{MG}$, and $\mathrm{U} 2-51 \mathrm{MG}$, combined with $10 \mu \mathrm{M}$ TMZ and $10 \mathrm{IU} / \mathrm{ml}$ IFN- $\beta$ : both concentrations are clinically achievable $(19,24)$. Ribavirin at $10 \mu \mathrm{M}$ is considered a clinically relevant concentration, because when administered at a dose of $800 \mathrm{mg} / \mathrm{day}$ as a therapeutic agent for chronic hepatitis $\mathrm{C}$, the blood concentration of ribavirin reached $13 \mu \mathrm{M}$ and the cerebral spinal migration of ribavirin was $70 \%(10,25)$. In addition, Casaos et al (11) employed $50 \mu \mathrm{M}$ ribavirin as a 
clinically appropriate concentration in their in vitro experiments. A very low concentration of ribavirin should help to reduce the adverse events of ribavirin, such as anemia, and be easier for clinical use. In addition, ribavirin is relatively inexpensive, and therefore beneficial in relation to the rising medical costs particularly of tumor treatment. Since the clinical use of triple combination therapy could lead to combined toxicity in patients, further studies are needed to investigate the extent of efficacy at various doses and times of use of these combinations.

In conclusion, we have provided evidence that ribavirin in combination with TMZ and IFN- $\beta$ can induce synergistic anti-tumor effects involving of cell growth inhibition in glioma cells, and could be of potential importance in the clinical setting.

\section{Acknowledgements}

The authors would like to thank Mr. Nobuo Miyazaki (Toray Industries Inc., Tokyo, Japan) for his discussions. Some parts of the present study have been included within a Japanese-language thesis submitted for the Ph.D. degree of Yushi Ochiai at Nihon University School of Medicine.

\section{Funding}

This work was supported in part by Grants-in-Aid for Scientific Research from the Japan Society for the Promotion of Science (grant no. 16K10772) and in part by a grant from the Health Sciences Research Institute, Inc. (Yokohama, Japan) for the Division of Companion Diagnostics, Department of Pathology and Microbiology, Nihon University School of Medicine.

\section{Availability of data and materials}

All data generated or analyzed during this study are included in this published article.

\section{Authors' contributions}

AY contributed to the experimental concept and design. YO and ES developed the experimental design, performed most of the experiments and some of the data analysis, and wrote part of the draft manuscript. KS and AY also conducted part of the data analysis and contributed to the writing of the manuscript. SYo, SYa and AO were involved in the conception and design of the study, undertook part of the experiments, analyzed the data, and contributed to the writing of the draft manuscript. TU, YS, TN, HH and YK supervised the study (including the experimental design), performed some of the experiments, analyzed data, helped prepare the draft manuscript, and proofread the manuscript. YO and KS contributed equally to this work. All authors read and approved the final manuscript.

\section{Ethics approval and consent to participate}

Not applicable.

\section{Patient consent for publication}

Not applicable.

\section{Competing interests}

The authors declare that they have no competing interests.

\section{References}

1. Stupp R, Hegi ME, Mason WP, van den Bent MJ, Taphoorn MJ, Janzer RC, Ludwin SK, Allgeier A, Fisher B, Belanger K, et al: Effects of radiotherapy with concomitant and adjuvant temozolomide versus radiotherapy alone on survival in glioblastoma in a randomised phase III study: 5-year analysis of the EORTC-NCIC trial. Lancet Oncol 10: 459-466, 2009.

2. Sidwell RW, Huffman JH, Khare GP, Allem LB, Witkowski JT and Robins RK: Broad-spectrum antiviral activity of Virazole: 1-beta-D-ribofuranosyl-1,2,4-triazole-3-carboxamide. Science 177: 705-706, 1972.

3. Kohli A, Shaffer A, Sherman A and Kottilil S: Treatment of hepatitis C: A systematic review. JAMA 312: 631-640, 2014.

4. Kentsis A, Topisirovic I, Culjkovic B, Shao L and Borden KL: Ribavirin suppresses eIF4E-mediated oncogenic transformation by physical mimicry of the 7-methyl guanosine mRNA cap. Proc Natl Acad Sci USA 101: 18105-18110, 2004.

5. Assouline S, Culjkovic B, Cocolakis E, Rousseau C, Beslu N, Amri A, Caplan S, Leber B, Roy DC, Miller WH Jr and Borden KL: Molecular targeting of the oncogene eIF4E in acute myeloid leukemia (AML): A proof-of-principle clinical trial with ribavirin. Blood 114: 257-260, 2009.

6. Borden KL and Culjkovic-Kraljacic B: Ribavirin as an anti-cancer therapy: Acute myeloid leukemia and beyond? Leuk Lymphoma 51: 1805-1815, 2010.

7. Ogino A, Sano E, Ochiai Y, Yamamuro S, Tashiro S, Yachi K, Ohta T, Fukushima T, Okamoto Y, Tsumoto K, et al: Efficacy of ribavirin against malignant glioma cell lines. Oncol Lett 8: 2469-2474, 2014.

8. De la Cruz-Hernandez E, Medina-Franco JL, Trujillo J, Chavez-Blanco A, Dominguez-Gomez G, Perez-Cardenas E, Gonzalez-Fierro A, Taja-Chayeb L and Dueñas-Gonzalez A: Ribavirin as a tri-targeted antitumor repositioned drug. Oncol Rep 33: 2384-2392, 2015.

9. Volpin F, Casaos J, Sesen J, Mangraviti A, Choi J, Gorelick N, Frieche J, Lott T, Felder R, Scotland SJ, et al: Use of an anti-viral drug, Ribavirin, as an anti-glioblastoma therapeutic. Oncogene 36: 3037-3047, 2017.

10. Ochiai Y, Sano E, Okamoto Y, Yoshimura S, Makita K, Yamamuro S, Ohta T, Ogino A, Tadakuma H, Ueda T, et al: Efficacy of ribavirin against malignant glioma cell lines: Follow-up study. Oncol Rep 39: 537-544, 2018.

11. Casaos J, Huq S, Lott T, Felder R, Choi J, Gorelick N, Peters M, Xia Y, Maxwell R, Zhao T, et al: Ribavirin as a potential therapeutic for atypical teratoid/rhabdoid tumors. Oncotarget 9: 8054-8067, 2018.

12. Saito R, Mizuno M, Hatano M, Kumabe T, Yoshimoto T and Yoshida J: Two different mechanisms of apoptosis resistance observed in interferon- $\beta$ induced apoptosis of human glioma cells. J Neurooncol 67: 273-280, 2004.

13. Yoshino A, Katayama Y, Yokoyama T, Watanabe T, Ogino A, Ota T, Komine C, Fukushima T and Kusama K: Therapeutic implication of interferon regulatory factor 1 (IRF-1) and IRF-2 in diffusely infiltrating astrocytomas (DIA): Response to (IFN)-beta in glioblastoma cells and prognostic value for DIA. J Neurooncol 74: 249-260, 2005.

14. Vannucchi S, Chiantore MV, Mangino G, Percario ZA, Affabris E, Fiorucci $\mathrm{G}$ and Romeo G: Perspective in biomolecular therapeutic intervention in cancer: From the early to the new strategies with type 1 interferons. Curr Med Chem 14: 667-679, 2007.

15. Yoshino A, Tashiro S, Ogino A, Yachi K, Ohta T, Fukushima T, Watanabe T, Katayama Y, Okamoto Y, Sano E and Tsumoto K: Gene expression profiles predicting the response to IFN- $\beta$ and a combination of temozolomide and IFN- $\beta$ in malignant gliomas. Int J Oncol 39: 529-542, 2011.

16. Yoshida J, Kajita Y, Wakabayashi T and Sugita K: Long-term follow-up results of 175 patients with malignant glioma: Importance of radical tumor resection and post-operative adjuvant therapy with interferon, ACNU and radiation. Acta Neurochir 127: 55-59, 1994.

17. Natsume A, Ishii D, Wakabayashi T, Tsuno T, Hatano H, Mizuno M and Yoshida J: IFN-beta down-regulates the expression of DNA repair gene MGMT and sensitizes resistant glioma cells to temozolomide. Cancer Res 65: 7573-7579, 2005. 
18. Park JA, Joe YA, Kim TG and Hong YK: Potentiation of anti-glioma effect with combined temozolomide and interferon-beta. Oncol Rep 16: 1253-1260, 2006.

19. Yoshino A, Ogino A, Yachi K, Ohta T, Fukushima T, Watanabe T, Katayama Y, Okamoto Y, Naruse N and Sano E: Effect of IFN-beta on human glioma cell lines with temozolomide resistance. Int J Oncol 35: 139-148, 2009.

20. Schlosser SF, Schuler M, Berg CP, Lauber K, Schulze-Osthoff K, Schmahl FW and Wesselborg S: Ribavirin and alpha interferon enhance death receptor-mediated apoptosis and caspase activation in human hepatoma cells. Antimicrob Agents Chemother 47: 1912-1921, 2003

21. Teng L, Ding D, Chen Y, Dai H, Liu G, Qiao Z and An R: Anti-tumor effect of ribavirin in combination with interferon- $\alpha$ on renal cell carcinoma cell lines in vitro. Cancer Cell Int 14: 63, 2014.

22. Yoshino A, Ogino A, Yachi K, Ohta T, Fukushima T, Watanabe T, Katayama Y, Okamoto Y, Naruse N, Sano E and Tsumoto K: Gene expression profiling predicts response to temozolomide in malignant gliomas. Int J Oncol 36: 1367-1377, 2010.

23. Wischhusen J, Naumann U, Ohgaki H, Rastinejad F and Weller M: CP-31398, a novel p53-stabilizing agent, induces p53-dependent and p53-independent glioma cell death. Oncogene 22: 8233-8245, 2003.
24. Ostermann S, Csajka C, Buclin T, Leyvraz S, Lejeune F, Decosterd LA and Stupp R: Plasma and cerebrospinal fluid population pharmacokinetics of temozolomide in malignant glioma patients. Clin Cancer Res 10: 3728-3736, 2004.

25. Naik GS and Tyagi MG: A pharmacological profile of ribavirin and monitoring of its plasma concentration in chronic hepatitis $\mathrm{C}$ infection. J Clin Exp Hepatol 2: 42-54, 2012.

26. Chou TC: Theoretical basis, experimental design, and computerized simulation of synergism and antagonism in drug combination studies. Pharmacol Rev 58: 621-681, 2006.

27. Ren H, Tan X, Dong Y, Giese A, Chou TC, Rainov N and Yang B Differential effect of imatinib and synergism of combination treatment with chemotherapeutic agents in malignant glioma cells. Basic Clin Pharmacol Toxicol 104: 241-252, 2009.

28. Kast RE, Skuli N, Cos S, Karpel-Massler G, Shiozawa Y, Goshen R and Halatsch ME: The ABC7 regimen: A new approach to metastatic breast cancer using seven common drugs to inhibit epithelial-to-mesenchymal transition and augment capecitabine efficacy. Breast Cancer 9: 495-514, 2017.

29. Stewart WE, Gosser JB and Lockart Jr RZ: Priming: A nonantiviral function of interferon. J Virol 7: 792-801, 1971.

This work is licensed under a Creative Commons Attribution-NonCommercial-NoDerivatives 4.0 International (CC BY-NC-ND 4.0) License. 